\title{
Selective activation of hippocampal guanylyl cyclase by a novel NO mimetic nitrate ester
}

\author{
Brian Bennett ${ }^{*}$, James Reynolds ${ }^{1}$ and Greg Thatcher ${ }^{2}$
}

\author{
Address: ${ }^{1}$ Department of Pharmacology \& Toxicology, Queen's University, Kingston, ON, Canada and ${ }^{2}$ Department of Medicinal Chemistry \& \\ Pharmacognosy, College of Pharmacy, University of Illinois at Chicago, Chicago, IL, USA \\ Email: Brian Bennett* - brian.bennett@queensu.ca \\ * Corresponding author
}

from $3^{\text {rd }}$ International Conference on cGMP Generators, Effectors and Therapeutic Implications

Dresden, Germany. I5-17 June 2007

Published: 25 July 2007

BMC Pharmacology 2007, 7(Suppl I):P6 doi:I0.I I86/I47|-22 I0-7-SI-P6

This abstract is available from: http://www.biomedcentral.com//47I-22 I0/7/SI/P6

(c) 2007 Bennett et al; licensee BioMed Central Ltd.

Studies of the distribution of $\alpha_{1}$ and $\alpha_{2}$ subunits of soluble guanylyl cyclase (sGC) indicate that the $\alpha_{2}$ subunit is expressed in relatively high abundance in brain, and is the major alpha subunit present in the hippocampus. Furthermore, the $\alpha_{2}$ subunit interacts with a PDZ domain of PSD95, a scaffolding protein that couples the NMDA receptor to neuronal nitric oxide synthase. Thus a membrane-bound NO-sensitive sGC is present in the hippocampus, and has been suggested to be a component of a signal transduction complex important for modulation of synaptic transmission and plasticity. We recently completed a study in which a novel NO mimetic nitrate ester (GT1061) reversed cognitive deficits in a cholinergic depletion model of Alzheimer's disease [1]. Of interest was that comparison of sGC activation in broken cell preparations of aorta and hippocampus showed that GT1061 selectively increased enzyme activity in the hippocampus (16- to 20-fold in hippocampus vs. 2- to 3 fold in aorta), suggesting that the enhanced activation of hippocampal sGC by GT1061 could be due to selectivity of the drug for targeting the $\alpha_{2} \beta_{1}$ isoform of sGC.

In the current study, the activation of sGC by GT1061, nitroglycerin (GTN), and DEA/NO was examined in various subcellular fractions of rat hippocampus $(25,000 \times \mathrm{g}$ supernatant fraction, synaptosomes, lysed synaptosomal supernatant fraction and lysed synaptosomal membranes). In the hippocampal supernatant fraction, maximal sGC activation by DEA/NO (600-fold) was about 8fold and 28-fold greater that that by GTN and GT1061, respectively. In contrast, the maximal activation by DEA/ NO in hippocampal synaptosomes (15-fold) was only $2-$ 2.5 -fold greater than that by the two nitrate esters. The majority of the DEA/NO-activated sGC activity was present in the supernatant fraction, and additionally, there was a greater potency difference between DEA/NO and the two nitrates for sGC activation in the supernatant fraction than there was in the synaptosomes. sGC activity was further examined after lysis of synaptosomes. Enzyme activity was present in both the supernatant fraction of lysed synaptosomes and in synaptosomal membranes, although the majority of the DEA/NO-activated sGC activity present in the supernatant fraction. In synaptosomal membranes, all three compounds increased sGC activity to the same degree ( $8-10$ fold). Thus the characteristics of hippocampal sGC activation differ markedly between cytosolic and membrane-bound enzyme, with a wide variation in efficacy between different nitrovasodilators for activation of cytoplasmic sGC and similar efficacy for activation of the membrane-bound enzyme. To the extent that the cognition enhancing properties of GT1061 are due to stimulation of the NO/sGC/cGMP signal transduction system in the hippocampus, the greater relative efficacy of GT1061 for activation of membrane-bound hippocampal sGC compared to aortic cytosolic sGC predicts that the beneficial CNS actions of the drug will occur at lower plasma concentrations than will any potential undesirable hypotensive actions. Indeed, improved performance in a visual recognition memory task in cholin- 
ergic-depleted animals occurred at doses of GT1061 that had negligible effects on systemic blood pressure.

\section{References}

I. Bennett BM, Reynolds JN, Prusky GT, Douglas RM, Sutherland RJ, Thatcher GRJ: Cognitive deficits in rats after forebrain cholinergic depletion are reversed by a novel NO mimetic nitrate ester. Neuropsychopharmacol 2007, 32:505-513.

Publish with Biomed Central and every scientist can read your work free of charge

"BioMed Central will be the most significant development for disseminating the results of biomedical research in our lifetime. " Sir Paul Nurse, Cancer Research UK

Your research papers will be:

- available free of charge to the entire biomedical community

- peer reviewed and published immediately upon acceptance

- cited in PubMed and archived on PubMed Central

- yours - you keep the copyright

Submit your manuscript here:

http://www.biomedcentral.com/info/publishing_adv.asp 